\title{
APROXIMACIÓN A LA FORMACIÓN ÉTICA Y POLÍTICA DE LOS ESTUDIANTES DE LA LICENCIATURA EN EDUCACIÓN BÁSICA PRIMARIA'

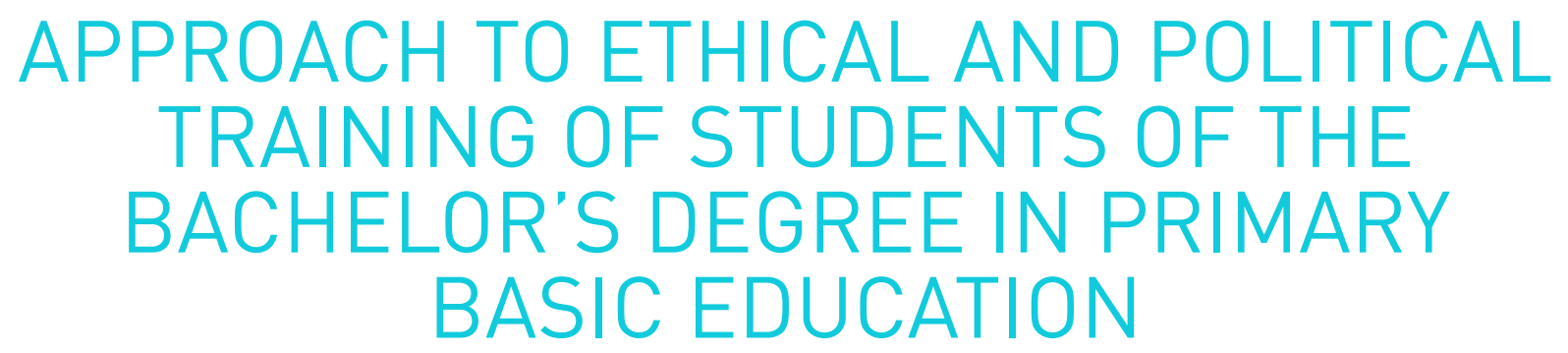

\author{
José Eriberto Cifuentes Medina*2 \\ Nubia Elena Pineda de Cuadros ${ }^{3}$ \\ Universidad Pedagógica y Tecnológica de Colombia \\ Martha Liliana Rodríguez Vivas ${ }^{4}$ \\ Fundación Universitaria Monserrate - Unimonserrate
}

\section{RESUMEN}

El artículo está en doble dirección: por una parte, resaltar la importancia de la formación Ética y Política de los estudiantes de la Licenciatura en Educación Básica Primaria futuro licenciado y por otra, la proyección de la imperante tarea de proyección formativa en quienes serán sus futuros educandos en los niveles de educación según su campo de acción. La formación Ética y Política de los estudiantes universitarios en el nivel de pregrado en relación a quienes

\footnotetext{
$1 \quad$ Artículo de investigación derivado del proyecto con código SGI 2932.

2 Investigador Asociado (I) SNCTel, convocatoria 833. Doctor en Educación, Universidad de Baja California-México. Magister en Educación, Especialista en Evaluación Educativa, Licenciado en Teología, Licenciado en Filosofía y Educación Religiosa, Universidad Santo Tomás. Especialista en Pedagogía y Docencia, Fundación Universitaria del Área Andina. Profesor de la Licenciatura en Educación Básica Primaria, Facultad de Estudios a Distancia, Universidad Pedagógica y Tecnológica de Colombia. Orcid ID: https://orcid.org/0000-0001-5702-620X Contacto: joseeriberto.cifuentes@uptc.edu.co 3 Doctora en Historia, Magíster en Historia, Licenciada en Ciencias Sociales y Económicas Universidad Pedagógica y Tecnológica de Colombia. Directora de la Escuela de Ciencias Humanísticas y Educación. Integrante del grupo de Investigación SIEK. Docente-investigadora Universidad Pedagógica y Tecnológica de Colombia. Contacto: nubia.pineda@uptc.edu.co $4 \quad$ Doctorando en Educación con Énfasis en Didáctica y Pedagogía. Atlantic International University, Magíster en Educación con Énfasis en el Aprendizaje de la Lecto escritura. Universidad Externado de Colombia, Licenciada en Educación Preescolar, Fundación Universitaria Monserrate - Unimonserrate. Directora Programa Licenciatura en Básica Primaria de la Fundación Universitaria Monserrate. Orcid https://orcid.org/0000-0002-9232-7099 Contacto: marthali1109@hotmail.com
} 
se forman para ser profesores de Educación Básica Primaria, corresponde ahondar en sus concepciones e imaginarios que coadyuven en la correlación entre la teoría y la praxis. Por ello se considera necesario y pertinente profundizar en la formación ética y política del licenciado, en relación a lo conceptual y su proyección práctica, en aras de responder a la misión, visión, objetivos y justificación del programa.

El licenciado en Educación Básica Primaria, que por convicción y vocación ha elegido por sí mismo ingresar a la educación superior a fortalecer su formación en el campo de la educación, la pedagogía y la didáctica de frente a responder al ejercicio docente según el perfil ocupacional y profesional y de acuerdo a las políticas educativas de Colombia. Ha de ser competente en el contexto propio de su ejercicio de la docencia en las áreas fundamentales y obligatorias que establece la ley general de Educación, entre ellas: "Educación ética y en valores humanos y Ciencias sociales, historia, geografía, constitución política y democracia"; propósito que indaga, controvierte y propone el presente estudio.

PALABRAS CLAVE: Ética, Política, Formación de Licenciados, Educación Básica

\section{ABSTRACT:}

The point is in the double direction: on the one hand, highlighting the importance of Ethical Training and Politics of the Student of the Degree in Basic Education future graduated and by the other, the development of the Imperative Course in which future students will be in. the levels of education according to their field of action. The Ethical and Political Formation of University Students at the Pregrade Level in relation to those who are trained to be teachers of Primary Basic Education, corresponds to a background in their conceptions and imagery that assists in the correlation between theory and praxis. For this reason it is considered necessary and pertinent to deepen in the ethical and political formation of the graduate, in relation to the conceptual and its practical protection, in order to answer the mission, vision, objectives and justification of the program.

The graduate in Primary Basic Education, who by conviction and vocation has chosen by himself to enter higher education to strengthen his training in the field of education, pedagogy and didactics in order to respond to the teaching profession according to occupational profile and professional and in accordance with the educational policies of Colombia. He must be competent in the proper context of his teaching practice in the fundamental and obligatory areas which he establishes in the general education, among them: "Ethical education and human values and social sciences, history, geography, political constitution and democracy"; purpose that inquires, controversies and proposes the present studio.

KEY WORDS: Ethics, Politics, Graduate Training, Basic Education

\section{INTRODUCCIÓN}

La formación Ética y Política en el licenciado de Educación Básica Primaria, se hace valida en la medida que como estudiante universitario transcienda el panorama del pensum académico, le de vida a los contenidos y a los conceptos para que al final no solo sea el cumplimiento de actividades o tareas de una o varias asignaturas relacionadas a la Ética y la Política, que por el contrario se constituya en columna vertebral de su presencia en la Universidad y su proyección en el contexto y escenario educativo del presente advenidero como profesor en el nivel educativo de su formación.

La enseñanza y aprendizaje de la Ética y la Política, no es cuestión de solo aprehensión de contenidos y conceptos se necesita de personas comprometidas por esencia y existencia en el 
desarrollo social de una comunidad que no es solo su presencia de valor académico sino de liderazgo y proyección. Los hijos que le confiara cada familia, que luego son y serán el presente y futuro de una comunidad que recuerda y valora de manera entrañable la labor del docente ha de cobrar vida por el compromiso de la formación Ética y Política de los estudiantes que le confía la sociedad. Es un reto y un desafió la formación humana desde una perspectiva ética y política, en medio de cruciales situaciones que contradicen la proyección de esta realidad.

\section{LA POLÍTICA Y LA VIDA POLÍTICA}

La política no siempre ha existido como una ciencia propiamente dicha, pero su expresión como la actividad humana dentro de las sociedades, una vez estas existieron, tuvo un espacio muy significativo que se hizo patente en la forma de organizarse, los modos de distribuir el poder y los compromisos comunes que se establecieron.

Las primeras aproximaciones a la política se encuentran en las grandes culturas de Mesopotamia y Egipto, pues en ellas se dio mayor desarrollo de las formas de gobierno monárquico e imperialista, aquí el arte de gobernar radicaba en el proceso individual de cada gobernante y su capacidad para mantener unido a su pueblo, ganar las guerras, alcanzar grandes conquistas y obtener la posesión de territorios y dominar las tribus e imperios cercanos.

Ya en la Grecia antigua, con Aristóteles y su obra Política, se sistematizaban los principios y las formas de cómo se debe llevar a cabo el arte de gobernar. Allí se destacan algunas características esenciales, por ejemplo en el ámbito político, el bien común debe prevalecer sobre el bien individual. Además, el gobierno debía estar en manos de los sabios, de los que pensaban y manejaban la razón. La política se confunde en cierto punto con la ética, lo cual garantizaba que la persona que gobernaba no busca sólo su bienestar individual sino y sobre todo, el de la comunidad.

De ese modo, la política se convierte en una característica más importante de la persona, tanto que Aristóteles llega a definir a la persona como: "animal político". Para él, toda persona está llamada a ejercer política desde el rol que ocupa en la sociedad que se encuentra.

Desde allí aprendemos que la participación activa de cada persona en su sociedad es muy importante para que se pueda llegar al bien común. Ninguna persona debe sentirse fuera de la política, pues casi es una obligación moral el vincularse con lo que suceda en sociedad. La plaza es el lugar de encuentro y el sitio donde se hace la política. El lugar donde cada una de las personas puede expresar libremente lo que piensa y lo que realizará una vez se encuentre frente a la comunidad que lo elija para gobernar. Unida a la plaza esta la oratoria, el arte de hablar y de hablar bien. Este uno de los dones que debe tener la persona que decide estar al frente de una sociedad. La palabra entonces juega un papel muy importante, pues de ella depende que las demás personas crean y se convenzan de su necesidad.

A partir de este planteamiento, a través de la historia las justificaciones al uso del poder y al privilegio de una clase sobre la otra han tenido que ver con la razón y, sobre todo, con la fuerza, en el desarrollo de acciones que demostraban la superioridad de unas personas sobre las otras. Sin embargo, el ejercicio de la política también ha traído beneficios a las sociedades. Por ejemplo, gracias a la organización política, los conflictos normales que existen en las diversas sociedades o grupos sociales se puedan resolver de manera pacífica. De este modo, la política juega un papel decisivo en las relaciones interpersonales y sociales, más aún, la política es un instrumento en las relaciones internacionales, pues permite buscar acuerdos 
o consensos con el fin de dirimir los conflictos y desarrollar planes y programas conjuntos.

La política tiene por función permitir el ano desarrollo de las sociedades, de tal manera que se opera como un árbitro entre los diversos grupos que conforman una sociedad y como la encargada de organizar la sociedad y de llevar todos los acuerdos a buen término. Las compañas educativas de los últimos años a este respecto han trabajado por recuperar el valor de la política, es decir, que se convierta de verdad en un ejercicio de la democracia y de la búsqueda del bien común y no en la forma de justificar los interés de unos pocos con deseos de poder y dominio.

\section{SENTIDO, SIGNIFICADO Y QUEHACER DE LA ÉTICA}

Hay quienes se cuestionan si la ética es una moda o una necesidad, si sirve para algo en un mundo tan complejo y que corre a unas velocidades inmensas. La ética tiene como objeto de estudio la vida práctica de las personas. Alli descubre los aspectos que sustentan y fundamentan las normas de actuación y de convivencia humana, y ayuda a las personas para que realicen sus proyectos de vida en sociedad. En este sentido se comprende que la ética tiene sentido y es una propuesta validad para el mundo de hoy.

Desde el punto de vista etimológico, ética viene del griego Ethos, que significa costumbre. En la mayoría de los diccionarios encontramos que ética es a ciencia que estudia las costumbres morales de los pueblos. Hasta aquí el significado de ética nos puede parecer fácil asimilar. Pero intentemos dar un paso más. ¿Qué podrá significar costumbre en Grecia? Tratando de ubicarnos en el contexto de la época, es decir, en una Atenas floreciente donde la vida intelectual era la que gobernaba la ciudad (polis), costumbre significaba todo aquello que venía de dentro de la persona, aquello que es de suyo de la persona.
En este sentido, se puede plantear que la ética tiene que ver con las actuaciones propias de las personas en medio de una ciudad o en medio de la sociedad en la cual se encuentran. La ética constituye el criterio por el cual una persona asume determinado comportamiento en su diario vivir, en su cotidianidad. En el concepto de ética no cabe la norma, pues las personas antes que guiarse orientarse por una norma, se obedecen a sí mismas, a sus deseos y aspiraciones más íntimas.

El ser humano siempre actúa de acuerdo con lo que él es en su constitución más profunda, la cual también está determinada por la sociedad y por el ambiente en el que crece y se desarrolla. Por tanto, no podemos pensar que existe una única ética validad para todas las sociedades y para todos los contextos. Se tiene que aceptar que la ética es contextual, es decir, depende de un contexto y es en él donde adquiere o no validez.

A lo largo de la historia se han propuesto diversos modelos éticos que han intentado dar respuesta a la pregunta: ¿Cómo ser feliz? Pues la felicidad siempre ha sido entendida como el bien ultimo al que está llamada la existencia humana. Esta respuesta se ha intentado dar desde tres perspectivas fundamentales, sin que agoten el extenso campo que pueda estudiar la ética.

Los universalistas. Son aquellas propuestas que buscan que su modelo de reflexión ética sea universal, es decir, pensar en un tipo de moral en la que todos estén de acuerdo y que se ajuste a todas las personas. Autores como Sócrates, Platón, Kant, Habermas, entre otros, han buscado que su propuesta ética tenga validez universal.

Los comunitaristas. Quienes señalan que el comportamiento humano no se puede analizar de manera individual, sino que debemos recurrir a la sociedad o a los grupos sociales. Consideran 
además que es dentro de la sociedad donde se perfila un tipo de comportamiento moral. La sociedad es el parámetro de vida y ella es quien determina y acepta las distintas formas de actuar y de comportarse.

Frente a las propuestas anteriores, surge la crítica contemporánea que las juzga como demasiado universales y que obligan a las personas a entrar en determinados ambientes o en grupos específicos. Por estos motivos la propuesta contemporánea es casi de tipo individual. Cada persona debe realizarse en su vida y comportarse como mejor considere. Propuestas como la de Nietzsche o Sartre son las que buscan darle a la persona, como ser individual, la posibilidad de guiar su vida por sí mismo, son necesidad de tener un parámetro o un grupo que lo esté llamando al orden o que le esté indicando u recordando los acuerdos de comportamiento moral.

\section{CONCEPCIONES DE LA DEMOCRACIA}

Es el gobierno escolar es la forma de vivenciar los procesos de democracia en la escuela por parte de los agentes educativos, enseñados por los padres de familia en cada hogar, implementados el docente en el aula, vividos con los compañeros, aprobado en el manual de convivencia escolar. Donde una vez terminados sus estudios se enfrentan a la realidad democrática de la sociedad y de acuerdo sus bases educativas recibidas podrán elegir o ser elegidos de manera democrática, es decir, que lo enseñado en la casa, vivido en la escuela se proyecta a la sociedad que se espera esté al servicio, sea para el beneficio común de las personas y progreso de los pueblos.

El campo de la organización escolar ha despertado un interés creciente en contextos académicos, sobre todo anglosajones, por el cambio en las perspectivas epistemológicas que sirven de apoyo a los análisis teóricos con los que llegar a comprender a las escuelas como organizaciones. Pero este cambio no se ha generalizado y se insiste en describir las dificultades que existen para aplicar las teorías de la organización al contexto escolar.

Se ha de reconocer que las fronteras epistemológicas, metodológicas y aplicativas de la organización escolar permanecen borrosas y cambiantes que según Santos Guerra (1997) sugiere atender a dos movimientos que tienen ida y vuelta en el fenómeno de la comprensión de una realidad "Fragmentación para llegar a una profundización mayor a través de la focalización en un campo o la contemplación de una perspectiva e Integración de todos los conocimientos para acceder a una visión comprensiva y globalizadora".

Concepciones de la democracia. El termino democracia viene del griego: Demos: Pueblo y Kratos: Poder o Gobierno; es decir: "Poder del pueblo" (Casas 2003). "En sentido amplio la democracia es una forma de convivencia social en la que todos sus habitantes son libres e iguales ante la ley y las relaciones sociales se establecen de acuerdo a mecanismos contractuales desde el punto de vista filosófico en la vida cotidiana". (Rodríguez 2008). Para la escuela se aplican las dos, al elegir sus representantes cada agente educativo se siente allí incorporado para defender o apoyar sus intereses pero asegurando la igualdad, la libertad y valores humanos al igual que las condiciones de una vida digna.

En cuanto a concepción del mundo nos conduce a uno de los ideales sublimes que el hombre intenta consolidar en la historia; ideal de la no arbitrariedad o autoritarismo, es decir, que exista participación del pueblo en sus decisiones, al igual que las personas sean consideradas ciudadanos y tengan derechos y deberes. También a ser elegir y ser elegidos para gobernar, desde los diferentes organismos que componen el gobierno escolar y los demás de la escuela. 
La democracia es un sistema de gobierno y un estilo de vida, por lo tanto, un sistema de gobierno se caracteriza porque es el pueblo quien toma las decisiones más importantes mediante la elección periódica de sus autoridades, a través de un voto libre, igualitario y secreto. Abraham Lincoln afirma: "La democracia es el gobierno del pueblo, por el pueblo y para el pueblo" (Rodríguez, 1996), de esta manera ha de existir un reconocimiento y respeto a los derechos fundamentales de las personas; por eso la democracia ha de ser un estilo de vida del estudiante desde el aula de clase. Eso significa que los comportamientos y actitudes personales, hacen posible que un ciudadano pueda contribuir a perfeccionar la democracia, pero que se puede iniciar desde los procesos de la escuela, la familia.

Retomando a algunos pensadores principalmente de edad antigua y moderna, Aristóteles afirma: "La libertad es el principio fundamental de la constitución democrática. Esto es lo que acostumbra a decirse, implicando ello que solo en este régimen político pueden los hombres participar de la libertad, y a este fin apunta, según se afirma toda democracia" (Aristóteles, 2000). Ahora bien, uno de los caracteres de la libertad es el alternarse con la obediencia y el mando, y en efecto, "la justicia democrática, consiste en la igualdad por el número y por el mérito, y siendo esto lo justo, de necesidad tiene que ser soberana la masa popular y estimarse como final y justa la decisión de la mayoría" (Aristóteles, 2000). De acuerdo con esta teoría todos los ciudadanos han de estar en pie de igualdad, por más que lo que resulta en las democracias es que los pobres tienen más poder que los ricos puesto que son más en número y soberana la decisión de la mayoría.

Jhon Locke en su obra "Tratado sobre el gobierno civil", demuestra que todo gobierno ha de estar fundamentado en un contrato entre el soberano y los súbditos. Un buen gobierno debe tener la separación de poderes y propone: el ejecutivo, legislativo y judicial. Locke dice: "la razón enseña a los hombres las leyes de la naturaleza como verdades eternas que dan lugar a los derechos naturales e inalienables del individuo" (Locke, 1995), igualmente en Rousseau, en su obra " $E I$ contrato social", expresa que: "los ciudadanos de una nación tienen igualdad de derechos y participación de la soberanía popular, cuya expresión es la ley la cual es el resultado de la voluntad general" (Rousseau, 2000).

Montesquieu en su obra "El espíritu de las leyes", señala que: "la influencia del clima y del ambiente en la organización política de los pueblos, defendió el gobierno constitucional y la decisión del poder público" (Montesquiu, 2000). Estas afirmaciones deben contribuir a una correcta organización del gobierno escolar con la participación de los estudiantes en las decisiones de la escuela, como ejemplo de proyección a futuro de la organización de su comunidad, ciudad, departamento y nación, de una adecuada educación democrática desde la escuela se puede garantizar jóvenes y personas que elegidas por el pueblo con el fin de que los representen puedan gobernar en pro de bien común y beneficio de todos.

Así mismo, Platón, Aristóteles y los estoicos hablan de la ley natural; esto cobra gran importancia en la Escolástica con Santo Tomas de Aquino, Francisco de Victoria y otros que elaboran las bases filosóficas de la ley natural que evoluciona en la edad moderna con: Thomas Hobbes que la transforma en una doctrina estructurada que hoy se conoce como derecho natural, luego Locke, Rousseau; consolida elementos de la democracia desde la perspectiva filosófica. 


\section{EDUCACIÓN PARA LA DEMOCRACIA}

El modelo político en las instituciones educativas recibe cada día mayor reconocimiento por parte de teóricos y prácticos. Para reconocer y comprender la dimensión política de las instituciones escolares es necesario relacionar dos enfoques que generalmente se presentan disociados. Por una parte, el enfoque interno, que persigue estudiar y analizar las escuelas como sistemas de actividad política - en cuyo caso estaríamos hablando de micro política educativa-, y, por otra, el enfoque estructural, que presenta a la escuela como un aparato del Estado, responsable sobre todo de la producción y reproducción ideológica.

Esta visión macro política de la escuela es necesaria, a su vez, para comprender su relación con el sistema económico, la justificación del currículo "oficial», el juego de intereses políticos e ideológicos que existen en la sociedad y en el sistema político en torno a la educación y a sus instituciones. Es necesaria la superposición de ambos enfoques para lograr un conocimiento más aproximado de la realidad. Por tanto, en la escuela se desarrollan, por una parte, dinámicas micro políticas (repartos de poder, conflictos, negociaciones, coaliciones), $\mathrm{y}$, por otra, dinámicas políticas, porque «la escuela desempeña, a través de sus prácticas y relaciones, un papel ideológico dentro del contexto sociocultural en el que está inmersa» (González, 1990).

La democracia y la formación ciudadana son conceptos a juicio muy estrechamente unidos. González (1998), citando a Kaplan (1997) y Dewey (1985) basándose en consideraciones sobre la democracia como forma de vida, denominada educación democrática: "aquella capaz de proporcionar, no meramente información sobre el mundo, sino una perspectiva clara de la forma que ciertas elecciones han afectado a nuestro modo de vida" (González, 1998), de tal manera que aporte a los alumnos un conocimiento y "un sentimiento de conexión entre lo que la sociedad escoge hacer y el control que es capaz de ejercer sobre las consecuencias de sus decisiones" (González, 1998). Por ello los estudiantes han de educar su conciencia para obrar con rectitud al elegir y ser elegido, la responsabilidad para asumir las consecuencias de su proceder al gobernar, liderazgo y compromiso para representar dignamente a quienes se lo confiaron, un estudiante se convierte en un líder.

Por ello vivir en democracia y para la democracia se requiere actitudes de aceptación, valoración y respeto, participación y colaboración entre los estudiantes y los actores educativos. Por ello la preparación que permite alcanzar un nivel deseable en esas actitudes se ha de gestar y adquirir en la escuela. En ella debe ser posible obtener conocimientos y hábitos de convivencia democrática, así como experiencias de participación responsable en actitudes e instancias sociales de la escuela y posteriormente del estado.

Más que compartir valores será preciso compartir actitudes, pues un objetivo clave de esta participación ha de ser el desarrollo de la reflexión. Esta deliberación ha de conducir a los estudiantes a preguntarse, a buscar respuestas y evaluar el propósito y significado de sus propias actividades. Dicha preocupación y los hábitos de participación responsable en actividades colectivas irán contribuyendo a la creación de un clima en el aula extrapolable al exterior, es decir, su familia y la comunidad donde vive, debe conllevar a los estudiantes se preparen para sumir compromisos desde la misma vida en adelante, mantener sus opiniones, asumir retos, confrontar ideas y habituarse a la discrepancia con prudencia, respeto, argumentos, rectitud de manera que conlleve al bien personal y colectivo.

El enfoque micro político de las escuelas ha recibido poca atención de teóricos e 
investigadores, ocupa poco espacio en las teorías de la organización, y menos todavía en las de gestión (Hoyle, 1986). Es un tema tabú en los debates serios, mientras que lo es de cotilleo en los encuentros informales, en los que se habla de «juego político», de «agendas ocultas», de «mafias organizativas» y de "maquiavelismo». Son temas que se abordan en la sala de profesores, en la cafetería y en los pasillos de la escuela, $y$, raramente, en un contexto más académico que propicie un análisis riguroso. Ello hace que se sepa poco de ese lado de la organización, que permanece oscuro.

Las escuelas son particularmente propicias a la actividad micro política por dos razones: porque, como ya hemos apuntado, son organizaciones débilmente articuladas, entre cuyos espacios o intersticios puede florecer mucha actividad, y porque las formas de legitimación compiten en la toma de decisiones. Esto último se debe a que la legitimidad formal del director es desafiada por formas profesionales y democráticas alternativas, que son especialmente válidas para las escuelas. Tal situación coloca a los directores ante el problema de equilibrar su responsabilidad con las expectativas de la colegialidad (Hoyle, 1986).

El poder en la escuela se constituye en un aspecto que atañe al ámbito escolar implica comprender el sentido que ésta tiene para estudiantes, maestros, padres y madres de familia, en cuantos actores involucrados en el proceso educativo. La democracia, "como actitud frente a la vida, dice también de la cultura de un grupo humano en un escenario determinado. Una actitud democrática es, ante todo, un acto del ser pensante que busca adoptar deliberadamente una postura frente a las interacciones, desde el reconocimiento de sí mismo y de los otros" (Borrero, 2003), en este sentido la democracia es una construcción colectiva que exige una verdadera reflexión.

La escuela se constituye en un espacio de relaciones, en cuya cotidianidad se configura una micro cultura propicia para la micro política. En ella bien podría constituirse el significado de la democracia y de los derechos humanos, siendo a su vez escenario de los compromisos de acción que estos generan. Se podría tomar apartes del libro "Educación y democracia: un campo de combate" del filósofo Estanislao Zuleta, pero de manera especial en el capítulo titulado: "La participación democrática y su relación con la educación". Afirma Estanislao: "Hay un sentido de la democracia que consiste en dar derecho al otro para que exponga y desarrolle su punto de vista... Democracia es dejar que los otros existan y se desarrollen por sí mismos. Llamamos democracia al derecho al derecho del individuo a diferir de la mayoría, a pensar y vivir distinto; en síntesis: el derecho a la diferencia" (Citado por Borrero 2003).

Desde la casa de enseña y aprende la democracia pero en la escuela se comparte con otros fuera del núcleo familiar se hace necesario cultivar el derecho a la diferencia en todo el marco de la palabra, diferencia de raza, religión, credo, genero, etc. Es donde el niño afianza este y muchos valores en el enlace de una relación social con los demás niños y los actores de la comunidad educativa.

En el capítulo: "La participación democrática y su relación con la educación", Estanislao aborda elementos muy importantes acerca de la democracia como sus dificultades, sus fragilidades, modestias y su relación con la educación. "Hay muchas cosas que se imponen a los niños, que también nos impusieron a nosotros y que, aunque perfectamente arbitrarias, son necesarias. Hay normas que son comunes a todos porque son prerrequisitos para podernos entender..." (Estanislao, 1995). A 
pesar de normas preestablecidas también otras se pueden concertar a través de la democracia y el gobierno escolar para ser consignadas en el manual de convivencia. Por ello es importante que permitir actuar a los niños con espontaneidad, pero es necesario orientar con toda franqueza acerca de lo que está bien o no, para que puedan tener la satisfacción de hacer las cosas bien.

En la educación que se brinda en la escuela es importante adquirir el amor a vencer las dificultades reales, a través de su participación y el ejercicio de la democracia, de elegir y ser elegido, se expresa la espontaneidad sin temor, ni miedo, sino que se es capaz de demostrar la valentía con respeto y responsabilidad por sí mismo y los demás, capaz de plantear soluciones acertadas a problemáticas reales y buscar ayuda para transformar la realidad.

\section{GOBIERNO ESCOLAR}

281 Se puede considerar el gobierno escolar como una forma de acercamiento a la democracia en la organización escolar. La democracia en el sistema educativo se constituye en un ambiente favorable para el desarrollo de los valores éticos, morales y cívicos de los estudiantes, desde la perspectiva de formación de futuros ciudadanos. Los procesos de democracia han de permitir la inclusión, la interculturalidad en medio de principios fundamentales como la participación de todos a elegir y ser elegidos para representar a sus demás compañeros en los diferentes entes de la institución educativa. Con el desarrollo de estas jornadas electorales en la escuela para su posterior ejercicio de representación, permite la construcción de cultura ciudadana.

Se abordara desde su concepto, propósitos y beneficios del gobierno escolar, como una organización de los niños, donde cada miembro participa democráticamente en actividades de la escuela; buscando el desarrollo socio-afectivo de los educandos.
El gobierno escolar es una estrategia social y metodológica que abre un espacio para que los alumnos se expresen como comunidad estudiantil responsable que propone desarrollar proyectos que les permitan generar y enriquecer su propia vida escolar. La ley 115 de 1994 (Capitulo IV, articulo 18) pretende que todos los miembros de la comunidad educativa conformada por estudiantes, padres de familia o acudientes, maestros, directivos docentes y administradores, ex alumnos y representantes del sector productivo; todos ellos según su competencia, participaran en el diseño, ejecución y evaluación del Proyecto Educativo Institucional y en la buena marcha del respectivo establecimiento educativo, es decir, el Gobierno Escolar es una respuesta a la necesidad de participación real y efectiva; exige toma de conciencia, compromiso, identidad profesional e institucional.

Propósitos del gobierno escolar son necesarios para el desarrollo dinámico de la comunidad educativa, como se evidencian en la Ley 115;

El fin del Gobierno Escolar es estimular el desarrollo socio-afectivo el niño e iniciarlo en la vida cívica y democrática. Esta innovación tiene como objetivo principal la integración de todos los elementos que componen la escuela, así como el desarrollo socio-afectivo e integral de los estudiantes. Desarrollar en los educandos actitudes y valores, mediante la participación democrática en las diversas actividades escolares. La Escuela Nueva a través de la acción del Gobierno Escolar, pretende devolverle al alumno su derecho de opinar, de participar, de integrarse al medio y de exigir un dialogo claro y razonable. La formación de valores como responsabilidad, honestidad, solidaridad, justicia, participación y otros de gran importancia para el niño. Formar y fomentar en los alumnos prácticas democráticas como la libre participación, el derecho de elegir y ser elegido. El Gobierno Escolar tiene como 
propósito principal la integración de la comunidad educativa; padres de familia, estudiantes y maestros.

El Gobierno Escolar es una respuesta a la necesidad de asociación real y efectiva, exige toma de conciencia, compromiso, identidad profesional e institucional; donde aparece la autonomía como realidad que debemos apoyar y reconocer promoviendo comunidades con participación, democracia, respeto a los derechos humanos y construcción de valores para la sociedad futura; con la mirada puesta en el niño, el adolescente, el adulto, el anciano, la familia y la escuela de una manera integrada hacia la transformación ciudadana.

La autonomía en el gobierno escolar implica responsabilidad, compromiso con el análisis sistemático de los problemas, exploración de las soluciones y la apertura indispensable para cualificar, enriquecer los proyectos institucionales y pedagógicos que se formulen ya que esto requiere trabajo colectivo, reflexiones, crítica constructiva y eficacia en la producción de alternativas, como cambios permanentes en función de mejorar la calidad de educación y formación.

El gobierno escolar es una oportunidad para que los niños generen actitudes de integración, trabajo en equipo, liderazgo, convivencia y conocimiento para la conservación de una escuela democrática a través del ejercicio práctico de la cívica mediante el voto programático, tarjetón, urna, revocatoria de mandato, campaña política entre otros aspectos del ejercicio de una democracia sana, donde hay la oportunidad para una adecuada educación para el ejercicio acertado de la democracia, desde la escuela.

\section{FUNCIÓN POLÍTICA DEL DOCENTE EN LA ESCUELA}

Conviene distinguir con toda claridad el papel político del educador como reproductor y transformador de la cultura y la formación integral de los estudiantes. La primera razón de la profesión docente es la relación con la sociedad, el maestro es por esencia un actor político, "de la calidad que tenga la formación escolar depende en alto grado la oportunidad de participar en las funciones de dirección del Estado..." (Cajiao, 2004).

Se hace necesario que en la escuela se brinden espacios de formación democrática y que el docente siendo un actor político y que desde su cátedra ha de conservar la neutralidad y prudencia para orientar, formar a los estudiantes sin matricularse en ningún partido o corriente política, para formar las mentes jóvenes en la dirección de los destinos de la sociedad con una preparación crítica.

Dentro de la escuela se hace necesario promover la participación activa de los estudiantes en la gestión escolar. Es muy fácil de boca para afuera y en la teoría pero difícil de llevar a la práctica, pues implica ceder y poder. Una organización democrática se opone a una organización autocrática, pero desafortunadamente en la escuela reina casi siempre lo segundo, y si no veamos la implementación de la disciplina y las formalidades de: horarios, uniformes, silencio y todas las prohibiciones que si bien hacen parte de la formación no hay una adecuada ejecución.

El conocimiento y la comprensión del proceso de grupo es la contribución más importante que el maestro puede hacer a cualquier conjunto de niños. Por ello el maestro "debe atraer la atención de los niños hacia ese proceso, por la misma forma como él mismo trabaje. El maestro pone en movimiento y guía su desarrollo" (Lindberg, 1961), el maestro debe aprender las aptitudes que demandan la definición de las necesidades de planes y la labor conjunta para realizarlos, así como utilizar los resultados de una valoración cuidadosa y para ello requiere mucha práctica y mucho estudio. No se puede esperar que los 
niños y jóvenes aprendan tales cosas solo por el hecho de escuchar las explicaciones y aquello que en la teoría.

Al respecto Lindberg (1961) el deber del "maestro es ayudar a los niños a examinar los problemas y a recurrir al proceso de un grupo en busca de su solución. A los niños se les puede enseñar a que reconozcan la importancia de todos los elementos que figuran en el proceso de la democracia" (p. 16), y además adquieran pericia en el empleo de ellos y de los valores que se requieren para la rectitud del desarrollo del proceso. El maestro no necesitara dedicar todo su tiempo y toda su atención a lo técnico y procedimental sino que especialista del proceso democrático prestara sus servicios en muchas direcciones.

El maestro necesita conocer y comprender las características de los niños, debe tener amplia práctica y desear que su experiencia aumente. Para trabajar en la forma democrática $\begin{array}{lllll}2 & 8 & 3 & \text { se necesita pensar profundamente acerca de }\end{array}$ muchos asuntos, tanto desde el nivel del niño como desde el nivel del adulto. El maestro debe conocer perfectamente los problemas de la comunidad, para sí poder ayudar a los niños encuentren la forma de estudiar y resolver aquellos problemas que les afectan más directamente.

El maestro, "necesita también comprender los problemas sociales, en su niveles local, nacional e internacional, para ayudar a los niños a que vean esos mismos problemas desde un punto de vista cada vez más amplio" (Lindberg, 1961), debe recurrir a la experiencia de los niños para ayudarlos y enseñarles a resolver los problemas y dificultades a través del proceso democrático.

Se ha de preparar a los maestros para que aparte de ser especialistas en el proceso también se constituyan en protagonistas del cambio educativo, en el sector educativo, "el papel de los docentes como protagonistas del cambio educativo" (Cárdenas, 2000), y dicho cambio se debe generar desde un proceso de democracia al interior de las escuelas y que luego debe transcender al exterior de las mismas y en la edad de ciudadano del estudiante.

\section{EL PROFESOR DE EDUCACIÓN BÁSICA PRIMARIA}

El ser humano tiene en su esencia un vo-care, es decir, un llamado a cumplir una misión con su vida en el mundo. Algunos cuentan con la semilla en sí mismo de ser servidores de los demás a través de algo que es propio solo para los humanos y es el educare; conducir a sus semejantes por el camino del conocimiento. Ellos son los profesores, también conocidos como docentes o maestros, reconocidos como profesores de una disciplina y con la convicción de guiar a niños, adolescentes, jóvenes y adultos a descubrirse a sí mismo, a aprender unas competencias, construir conocimiento, manifestar la realidad, ver la vida de otra forma, forjar un futuro mejor y a defenderse en la vida.

Hombres y mujeres emprenden el cumplimiento de su misión como profesores, algunos de ellos se inician desde la formación en las Escuelas Normales Superiores, en la formación pedagógica y didáctica propia para el ejercicio de la enseñanza. Según Duque Linares en sus obras: "El arte de ser Maestro" y "La misión de educar", a la luz de la realidad se hace una reflexión sobre el educar como un arte, en el acto educativo y pedagógico y en el proceso de enseñanza y aprendizaje, entre el maestro y el estudiante.

En el ejercicio de la docencia especialmente en licenciados se ha de notar el compromiso por la tarea que le ha sido encomendada, por ello ha der ser feliz, pero ¿Cómo se sabe si es o no feliz?, afirma Duque que; "Cuando un maestro es feliz, es porque le gusta la docencia, lleva la pedagogía en la sangre, ve a sus alumnos como a sus hijos, él asume su papel de padre, 
los quiere y se preocupa por su futuro" (Duque, 2001). La coherencia del maestro con su quehacer es un arte, por ello educar es algo más que un trabajo, más que enseñar una disciplina; es en verdad una entrega total por formación integral y la búsqueda de la perfección de sus estudiantes en pro de una vida digna.

El actor principal es el hombre en sí mismo. "la consideración del ser humano como ser capaz de educarse: EDUCABILIDAD, la necesidad de agentes externos capaces de colaborar en el proceso educativo de los otros" (Horca, 2008). Pudiéndose diferenciar el educador en la línea personal, institucional e impersonal y el educador ha de contar con las cualidades físicas, psicológicas, intelectuales, éticas y estéticas entre otras. Por ello ha de tener funciones como: aporte a la cultura personal, búsqueda y asimilación de la cultura, regulación en el proceso del aprender, estimulación en la actividad del educando y evaluación de lo aprendido; así, el maestro es el verdadero profesional de la educación, con el apoyo de la filosofía, se ha de convertir en un gran maestro de la vida, que por misión ha de contribuir con la perfectibilidad de sus congéneres.

El profesor de básica primaria ha de estar preparado y formado para enseñar los contenidos de las áreas obligatorias y fundamentales que señala la ley 115 :

Ciencias naturales y educación ambiental, Ciencias sociales, historia, geografía, constitución política y democracia, Educación artística, Educación ética y en valores humanos, 5. Educación física, recreación y deportes, Educación religiosa, Humanidades, lengua castellana e idiomas extranjeros, Matemáticas, Tecnología e informática (Artículo 23)

Y las demás áreas que con las reformas de los últimos años se han hecho visibles y obligatorias como el caso de: Catedra de la Paz, según la Ley 1732 de 2014 y el Decreto 1030 de 2015.
Su tarea es fomentar la felicidad de los niños de básica primaria que tiene a cargo, a través de la enseñanza de los contenidos y de las experiencias, promoviendo a través de los estilos de enseñanza, pero también de los estilos de aprendizaje la construcción conceptual y también de la vida como una posibilidad para entender la calidad de vida de un sujeto, pero también de la participación en la comunidad de manera social.

\section{CONSIDERACIONES FINALES}

El estatus epistemológico de análisis se centra en saber acerca de las organizaciones escolares, perspectiva política de las escuelas, el enfoque micro político, los intereses en juego: los grupos de interés, el poder en la escuela, el control de los directores en la escena micro política, la falacia de definir al centro como una comunidad escolar: la ausencia de participación de los actores y las estrategias micro políticas; para confrontar la denodada labor del corpus directivo y las causas y consecuencias de las decisiones al igual que la interacción de la micro y marco política en el proceder de los mismos y de la comunidad educativa.

El ejercicio de la democracia en la escuela se puede evidenciar la propuesta del gobierno escolar, es allí donde se puede evidenciar y concretar el acercamiento a vivir la democracia en la comunidad educativa y una brillante estrategia de integrar a los diferentes actores educativos: padres de familia, maestros, estudiantes y comunidad en general; con el fin de construir sociedad más justa y equitativa desde la escuela, donde se comienzan a forjar grandes líderes estudiantiles y a futuro líderes de la sociedad con nuevas alternativas de solución a problemas y necesidades de interés comunitarios.

El docente de frente a los cambios sociales y a la complejidad de los problemas, se hace necesario enfrentarlos con estrategias de acción 
desde el contexto con visión de globalidad, como una profesión de servicio en la construcción de conocimiento, pero también de seres humanos integrales y humanos para la edificación de una mejor sociedad y desde luego rescatar la integralidad de la profesión docente evitando el posible deterioro al cual se está enfrentando.

El rol del profesor de educación básica primaria, sin duda alguna esta mediado por la normatividad vigente en el sistema educativo colombiano. El punto de partida que a normatividad se refiere parte de la Constitución de 1991, se evidencia la educación como un derecho fundamental, acto seguido Ley 30 de 1992, Ley 115 de 1994 y desde luego todos los decretos reglamentarios en relación a la organización del sistema educativo colombiano. En necesario aclarar que el rol del profesor de Educación Básica Primaria transciende las barreras, los limites y las fronteras de la normatividad siendo esta apenas una forma de estandarizar la formación, profesionalización, capacitación, vinculación de los profesores; siendo visible su auténtico rol en cada escenario de la geografía colombiana que es diferente como lo es cada ser humano.

El rol del profesor de básica primaria también se enmarca si su desempeño profesional y laboral se da en el ámbito urbano o rural según sus propias connotaciones de diversidad espaciogeográfico-temporal; sea cual fuere su escenario, el campo de acción es el mismo: Básica Primaria en sus cinco grados de formación: primero, segundo, tercero, cuarto y quinto y para ello ha de estar preparado y cumplir a cabalidad con sus funciones y la enseñanza de los contenidos de las asignaturas obligatorias y fundamentales según la Ley 115. Con la calidad que requiere su perfil y con la apropiación de su enseñanza en la promoción del aprendizaje y la construcción de conocimiento de los educandos en cada grado y también en director de su propia sede puesto que es docente y también quien organiza y dirige su propia sede.

\section{REFERENCIAS BIBLIOGRÁFICAS}

Aristóteles, (2000). La Política $1^{\mathrm{a}}$ ed. Bogotá D. C. Ediciones Momo.

Cajiao, F. (2004). La formación de maestros y su impacto social. $1^{\mathrm{a}}$ ed. Bogotá: Magisterio.

Cajiao, F. (1994). Poder y justicia en la escuela colombiana. $1^{\text {a }}$ ed. Bogotá:

Fundación Santa fe de Bogota.

Casas, V. M. et al (2003). La democracia y sus retos en el siglo XXI. Elementos para la formación democrática de los jóvenes. $1^{\text {a }}$ ed. Barcelona: Graficas Muriel.

Cárdenas, A. L. et al. (200). El maestro protagonista del cambio educativo. $1^{a}$ ed. Bogotá D. C.: Magisterio.

Decreto 1075 de 2015, Único Reglamentario del Sector Educación.

Duque, L. J. (2001). El arte de ser Maestro. $2^{\mathrm{a}}$ Ed. Bogotá. Panamericana S. A.

Duque, L. J. (2001). La misión de educar. $2^{\mathrm{a}} \mathrm{Ed}$ Bogotá. Panamericana.

Jersild, A. T. (1964). El niño en la escuela. $1^{\mathrm{a}}$ ed. Buenos Aires: Editorial Paidos

Ministerio de Educación Nacional (1994), Ley $1151^{\text {a }}$ ed. Bogotá D. C. Colombia: Ediciones Momo.

Lindbrerg, L. (1961). La democracia en la escuela. $1^{\mathrm{a}}$ ed. México Ed. Letras.

Constitución Política De Colombia (2008). Edición actualizada. Bogotá D. C. Colombia: Ediciones Momo.

Dewey, J. (1990). Administración de las instituciones escolares. $1^{\mathrm{a}}$ ed. Bogotá: Universidad de la sabana.

Escobar, G. (1992). Ética: Introducción a su problemática y su historia. $3^{a}$ ed. México. Ed Mcgraw-Hill 
Esper, M. (2008). Cómo educar en valores éticos. $1^{\mathrm{a}}$ ed. México: Editorial Trillas

Escobar, G. (2000). Ética. $4^{\mathrm{a}}$ ed. México. Editorial Mcgraw-Hill

González, F. J. et al (1998). "Educar para la democracia. La ciencia-Tecnología-sociedad". Investigación en la escuela. Democracia y renovación de la escuela.

Maturana, H. (1997). La democracia es una obra de arte. $1^{\text {a }}$ ed. Colombia: Ed Magisterio.

Montesquieu, (2000). El espíritu de las leyes $1^{\text {a }}$ ed. Bogotá D. C. Ed. Momo.

Pérez, G. (1997). Cómo educar para la democracia. $1^{\text {a }}$ ed. Madrid: Ed. Popular

Rodríguez, M. (2008). La democracia como una forma de vida en el aula del grado $5^{\circ} \mathrm{D}$ en la institución educativa San Marcos de Muzo Boyacá. $1^{\mathrm{a}}$ ed. Tunja

Colombia.

Rousseau, J. J. (2000). El contrato social. $1^{\mathrm{a}}$ ed. Bogotá D. C.: Ediciones Momo

Santos, G. M A. (1996). "La democracia, un estilo de vida". Cuadernos de Pedagogía. Barcelona, 251 50-54 [Octubre]

Zuleta, E. (1995). Educación y democracia. Un campo de combate. $2^{\mathrm{a}}$ ed. Bogotá: Corporación Tercer Milenio. 